\title{
Recommended Changes to Specifications for Demand Controlled Ventilation in California's Title 24 Building Energy Efficiency Standards
}

\author{
W.J. Fisk, D.P. Sullivan, D. Faulkner \\ Environmental Energy Techologies Division \\ Indoor Environment Department \\ Lawrence Berkeley National Laboratory \\ Berkeley, CA 94720
}

April 8, 2010

The research reported here was supported by the California Energy Commission Public Interest Energy Research program award number 600303000 and by the Assistant Secretary for Energy Efficiency and Renewable Energy, Office of the Building Technologies Program, U.S. Department of Energy under Contract No. DE-AC02-05CH11231. 


\title{
Recommended Changes to Specifications for Demand Controlled Ventilation in California's Title 24 Building Energy Efficiency Standards
}

\author{
Report to the California Energy Commission \\ Public Interest Energy Research Program
}

April 8,2010

\begin{abstract}
AUTHOR
William J. Fisk, Principal Investigator

Douglas P. Sullivan and David Faulkner

Indoor Environment Department

Lawrence Berkeley National Laboratory

Berkeley, CA 94720
\end{abstract}

Commission Project Manager: Brad Meister

Agreement No. 600303000

PIER Subject Area: Buildings End Use Energy Efficiency Program 


\section{DISCLAIMER}

This report was prepared as the result of work sponsored by the California Energy Commission. It does not necessarily represent the views of the Energy Commission, its employees or the State of California. The Energy Commission, the State of California, its employees, contractors and subcontractors make no warrant, express or implied, and assume no legal liability for the information in this report; nor does any party represent that the uses of this information will not infringe upon privately owned rights. This report has not been approved or disapproved by the California Energy Commission nor has the California Energy Commission passed upon the accuracy or adequacy of the information in this report.

\section{ACKNOWLEDGMENT OF FINANCIAL SUPPORT}

The research reported here was supported by the California Energy Commission Public Interest Energy Research program award number 600303000 and by the Assistant Secretary for Energy Efficiency and Renewable Energy, Office of the Building Technologies Program, U.S. Department of Energy under Contract No. DE-AC02-05CH11231. 


\section{INTRODUCTION}

In demand-controlled ventilation (DCV), rates of outdoor air ventilation are automatically modulated as occupant density varies. The objective is to keep ventilation rates at or above design specifications and code requirements and also to save energy by avoiding excessive ventilation rates. DCV is most often used in spaces with highly variable and sometime dense occupancy. In almost all cases, carbon dioxide $\left(\mathrm{CO}_{2}\right)$ sensors installed in buildings provide the signal to the ventilation rate control system. People produce and exhale $\mathrm{CO}_{2}$ as a consequence of their normal metabolic processes; thus, the concentrations of $\mathrm{CO}_{2}$ inside occupied buildings are higher than the concentrations of $\mathrm{CO}_{2}$ in the outdoor air. The magnitude of the indoor-outdoor $\mathrm{CO}_{2}$ concentration difference decreases as the building's ventilation rate per person increases. The difference between the indoor and outdoor $\mathrm{CO}_{2}$ concentration is also a proxy for the indoor concentrations of other occupant-generated bioeffluents, such as body odors [1].

Reviews of the research literature on DCV [2-4] indicate a significant potential for energy savings, particularly in buildings or spaces with a high and variable occupancy. Based on modeling [5], cooling energy savings from applications of DCV are as high as $20 \%$.

With support from the California Energy Commission and the U.S. Department of Energy, the Lawrence Berkeley National Laboratory has performed research on the performance of $\mathrm{CO}_{2}$ sensing technologies and optical people counters for DCV [6, 7]. In addition, modeling was performed to evaluate the potential energy savings and cost effectiveness of using DCV in general office spaces within the range of California climates [8].

The above-described research has implications for the specifications pertaining to DCV in section 121 of the California Title 24 Standard [9]. Consequently, this document suggests possible changes in these specifications based on the research findings. The suggested changes in specifications were developed in consultation with staff from the Iowa Energy Center who evaluated the accuracy of new $\mathrm{CO}_{2}$ sensors in laboratory-based research [10]. In addition, staff of the California Energy Commission, and their consultants in the area of DCV, provided input for the suggested changes in specifications.

\section{EXISTING SPECIFICATIONS IN TITLE 24 FOR DCV}

Appendix 1 reproduces verbatim the existing specifications for DCV in Title 24 and associated appendices. Key specifications relevant to this document are described in the following list:

1. DCV is required for spaces that have an air economizer; a design occupant density, or a maximum occupant load factor for egress purposes greater than or equal to 25 people per $1000 \mathrm{ft}^{2}$ (40 square foot per person); and that are either single zone systems with any controls; or multiple zone systems with Direct Digital Controls (DDC) to the zone level. There are exceptions to this requirement for certain types of spaces including as classrooms, call centers and medical facilities. 
2. For each system with $\mathrm{DCV}, \mathrm{CO}_{2}$ sensors must be installed in each room with no less than one sensor per $10,000 \mathrm{ft}^{2}$ of floor space. $\mathrm{CO}_{2}$ sensors must be located in the room between $3 \mathrm{ft}$ and $6 \mathrm{ft}$ above the floor or at the anticipated height of the occupants heads;

3. $\mathrm{CO}_{2}$ sensors shall be certified by the manufacturer to be accurate within plus or minus 75 ppm at a 600 and $1000 \mathrm{ppm}$ concentration when measured at sea level and $25^{\circ} \mathrm{C}$, factory calibrated or calibrated at start-up, and certified by the manufacturer to require calibration no more frequently than once every 5 years. Upon detection of sensor failure, the system shall provide a signal which resets to supply the minimum quantity of outside air to levels required by Section 121(b)2 to the zone serviced by the sensor at all times that the zone is occupied.

4. The $\mathrm{CO}_{2}$ sensor(s) reading for each zone shall be displayed continuously, and shall be recorded on systems with DDC to the zone level.

5. The acceptance requirement for DCV system include a functional test demonstrating that economizer system dampers open and close as intended to high and low $\mathrm{CO}_{2}$ concentrations

\section{KEY RELATED RESEARCH RESULTS}

This section briefly describes the key results of the California Energy Commission and U.S. Department of Energy supported research that serve as the technical underpinning for the subsequent recommended changes in the specifications for DCV in Title 24. These research findings are described in much greater detail in the following references [6-8]. Some of the text below was drawn directly from the cited documents.

\section{$\mathrm{CO}_{2}$ measurement accuracy [6]}

Studies of the accuracy of deployed $\mathrm{CO}_{2}$ sensors used for DCV in California indicate that a substantial fraction of $\mathrm{CO}_{2}$ sensors had errors greater than specified in Title 24. Forty seven percent of sensors had errors greater than $75 \mathrm{ppm}$ at a concentration of $760 \mathrm{ppm}$ and $40 \%$ of sensors had errors greater than $75 \mathrm{ppm}$ at a concentration of $1010 \mathrm{ppm}$. A significant fraction of sensors have much larger errors, e.g., larger than 300 ppm. These concentrations of 760 and $1010 \mathrm{ppm}$ are typical of the setpoint concentrations at which DCV systems increase outdoor air ventilation rates. Thus, overall many $\mathrm{CO}_{2}$ sensors do not meet accuracy requirements."

Sensors from some specific manufacturers and with particular design features had a better average accuracy than other sensors. However, use of sensors only in these categories, while helpful, would not result in widespread compliance with the Title 24 accuracy requirements. A significant number of sensors in all age categories had large errors. Thus, replacing sensors every few years also would not solve the accuracy problem.

Because the results obtained from energy management systems generally agreed well with results obtained from sensor displays, the measurement errors appear to be primarily a 
consequence of sensor problems and not a consequence of errors in translating the sensor output signals to building energy management systems.

In analyses of a sample of nine faulty sensors, four of the sensors had an output signal that was essentially invariable with $\mathrm{CO}_{2}$ concentration, yet these sensors were still deployed, indicating that facility managers are not always aware of obviously faulty sensors.

In a laboratory-based study of the accuracy of 15 models of new single-location $\mathrm{CO}_{2}$ sensors performed by the Iowa Energy Center, many of the new $\mathrm{CO}_{2}$ sensors had errors greater than 75 ppm, and errors greater than 200 ppm were not unusual. Maximum errors of new sensors approached 500 ppm.

Pilot-scale studies of the accuracy of multi-location $\mathrm{CO}_{2}$ monitoring systems were too limited for firm conclusions about the accuracy of these systems; however, the limited results obtained were encouraging. The study results illustrate the advantage of incorporating a measurement of outdoor air $\mathrm{CO}_{2}$ concentration with each sensor - offset errors cancel out in the indoor-outdoor $\mathrm{CO}_{2}$ concentration difference. For widespread acceptance, it seems likely that the costs of these systems will need to be reduced.

Together, the findings from the laboratory studies of the Iowa Energy Center and the field studies supported by the California Energy Commission indicate that many $\mathrm{CO}_{2}$ based DCV systems will fail to meet the design goals of saving energy while assuring that ventilation rates meet code requirements.

\section{Spatial Variability of $\mathrm{CO}_{2}$ concentrations in occupied meeting rooms [6]}

Multipoint measurements of $\mathrm{CO}_{2}$ concentrations in occupied meeting rooms were completed to provide information for locating the $\mathrm{CO}_{2}$ sensors in meeting rooms. The Title 24 standard requires that $\mathrm{CO}_{2}$ be measured between 0.9 and $1.8 \mathrm{~m}$ ( 3 and $6 \mathrm{ft}$ ) above the floor with no less than one sensor per $10,000 \mathrm{ft}^{2}\left(930 \mathrm{~m}^{2}\right)$ of floor area. In some of the meeting rooms, concentrations at different wall-mounted sample points varied by more than $200 \mathrm{ppm}$ and concentrations at these locations sometimes fluctuated rapidly. These concentration differences may be a consequence, in part, of the high concentrations of $\mathrm{CO}_{2}$ in the exhaled breath of nearby occupants. Because the results of the multipoint measurements varied among meeting rooms, this research does not result in definitive guidance for locating sensors in meeting rooms; however, the results suggest that measurements at return-air grilles may be preferred to measurements at wall-mounted locations. In four out of seven data sets, $\mathrm{CO}_{2}$ concentration at return-grille locations fell between the maximum and minimum of $\mathrm{CO}_{2}$ concentrations at wallmounted locations and in five of seven data sets, the period average concentration at return grilles was within $10 \%$ of the period average concentration measured from sample points on walls. 


\section{Performance of optical people counters [7]}

Pilot-scale studies evaluated the counting accuracy of two people counting systems that could be used in DCV systems, instead of $\mathrm{CO}_{2}$ sensors, to provide control signals for modulating outdoor air ventilation rates. The evaluations included controlled challenges of the people counting systems using pre-planned movements of occupants through doorways and evaluations of counting accuracies when naïve occupants (i.e., occupants unaware of the counting systems) passed through the entrance doors of the building or room. The two people counting systems had high counting accuracy accuracies, with errors typically less than $10 \%$, for typical nondemanding counting events. However, counting errors were high in some highly challenging situations, such as multiple people passing simultaneously through a door. Counting errors, for at least one system, can be very high if people stand in the field of view of the sensor. Both counting system have limitations and would need to be used only at appropriate sites and where the demanding situations that led to counting errors were rare.

\section{Energy savings potential from DCV in general office spaces [8]}

National level data indicate that average minimum ventilation rates in offices are either 28 or 80 cfm per person (13 or $38 \mathrm{~L} / \mathrm{s}$-person). The different average minimum ventilation rates are the result of different measurement protocols but both values are well above the minimum ventilation requirement in California which is approximately $15 \mathrm{cfm}$ per person (7 L/s-person). These numbers suggest potential energy savings from use of DCV in general offices to bring the average minimum ventilation rate into alignment with the Title 24 requirement. Modeling and cost analyses, performed to assess this potential, indicated that DCV would generally not be cost effective for general office spaces in California if existing office buildings have $28 \mathrm{cfm}$ per person (13 L/s-person) of ventilation but would often be cost effective if existing buildings have $80 \mathrm{cfm}$ per person (38 L/s-person) of ventilation.

\section{RECOMMENDATIONS}

Based on the research described above, many existing $\mathrm{CO}_{2}$-based DCV systems will fail to meet the design goals of saving energy while assuring that ventilation rates meet code requirements. However, the potential energy savings from properly operating DCV systems appear to be substantial in magnitude. Thus, it is appropriate to consider how the specifications for DCV in the Title 24 Standards could be changed in order to improve the performance of DCV systems. The following text describes recommended changes in specifications and a discussion of the recommendations. There is some overlap in the language within the various recommendations that should be removed if multiple overlapping recommendations are adopted.

\section{Recommendation 1}

Description of Recommendation 1

$\mathrm{CO}_{2}$ sensors installed in new installations of DCV shall have inlet ports and written protocols that make it possible to calibrate the deployed sensors using $\mathrm{CO}_{2}$ calibration gas samples. The inlet ports must provide paths for introducing calibration gas samples into the sensors. The protocols must provide the guidance that a facility manager or building control system 
professional needs to check and, if necessary, adjust the sensors' calibration' using, at a minimum, two calibration gas samples. The calibration protocol shall specify that one calibration gas sample has a $\mathrm{CO}_{2}$ concentration between 950 and $1050 \mathrm{ppm}$, with the actual concentration of the calibration gas known within \pm 2 percent. The protocol shall specify calibration with a second calibration gas concentration of either zero $\mathrm{ppm} \mathrm{CO}_{2}$ or between 450 and $550 \mathrm{ppm} \mathrm{CO}_{2}$, with the actual concentration of the calibration gas known within \pm 2 percent.

Exception: The inlet port and calibration protocol are not required if the sensor manufacturer or their agent maintains a sensor exchange program in which deployed sensors are replaced with new or used factory-calibrated sensors at least once per year.

\section{Discussion of Recommendation 1}

The accuracy of $\mathrm{CO}_{2}$ sensors used for DCV must be improved if DCV systems are to provide the intended energy and indoor environmental quality benefits. Based on the previously-described research [6], restricting the allowable sensor designs will not assure widespread compliance with the Title 24 accuracy requirements. $\mathrm{CO}_{2}$ measurement accuracy cannot be assured if sensors are not calibrated. Many sensors utilized today cannot practically be calibrated after deployment due to the absence of an inlet port and/or calibration protocol. This recommended change in Title 24 specifications would enable calibrations of all deployed sensors unless the manufacturer maintains a sensor exchange program in which deployed sensors are replaced with new or used factory-calibrated sensors at least once per year. The recommended changes in specifications would also provide incentives to manufacturers to offer sensor exchange programs.

Manufacturer's of sensors that already meet these requirement are likely to be supportive of the change in specifications. Many of the existing $\mathrm{CO}_{2}$ sensors marketed for DCV do not meet the requirements in this recommendation, thus, substantial industry opposition to the changes should also be expected. Also, it is important to note that making it possible to calibrate deployed sensors does not assure that the calibrations will actually be performed. A significant fraction of $\mathrm{CO}_{2}$ sensors already meet these requirements; however, in the field studies by the authors no facility manager reported that they had calibrated their $\mathrm{CO}_{2}$ sensors subsequent to the initial sensor installation period. It is hoped that as the results of research demonstrating large $\mathrm{CO}_{2}$ measurement errors become known, calibrations will become more common.

No analyses have been performed to determine if sensors meeting the requirements of Recommendation 1 have a significantly higher cost; however, compliant sensors are commonly used today suggesting that incremental costs, if any, are modest. The resulting energy savings will reduce energy costs by an amount that has not been determined.

An alternative or supplement to Recommendation 1 would be to establish an independent sensor validation program that periodically evaluates samples of sensors of various types. A one-time sensor evaluation after a new sensor is introduced into the market may not be adequate. Only sensors on a list of those that pass this program would be compliant with Title 24 requirements. It would be best if the program costs were not paid by sensor manufacturers so that the testing organization is not beholden to the sensor companies. Such a program would be expected to improve at least the initial accuracy of $\mathrm{CO}_{2}$ sensors used for DCV, it would not rely on facility managers to implement calibrations, and it would not restrict any sensor design features. A main 
drawback is the difficulty of establishing and financing of the independent sensor validation program. In addition, because sensor calibrations may change over the life of the sensor, such a sensor validation program would not assure that sensor accuracy is maintained.

\section{Recommendation 2}

\section{Description of Recommendation 2}

Within 60 days after installation in a building, all $\mathrm{CO}_{2}$ sensors installed for DCV shall be calibrated, using the manufacturer's recommended protocol, to assure $\mathrm{CO}_{2}$ measurements are accurate within $\pm 75 \mathrm{ppm}$. The protocol must check and, if necessary, adjust the sensor's calibration using, at a minimum, two calibration gas samples, one with a $\mathrm{CO}_{2}$ concentration between 950 and $1050 \mathrm{ppm}$ and the second with a $\mathrm{CO}_{2}$ concentration of either zero ppm or between 450 and $550 \mathrm{ppm}$. The concentration of the $\mathrm{CO}_{2}$ in the calibration gases shall be known within \pm 2 percent.

Exception: This calibration is not required if the sensor is provided with documentation demonstrating that a comparable calibration was implemented for the specific sensor within the past 90 days and that the sensor is accurate within $\pm 75 \mathrm{ppm}$ at $500 \pm 50$ and $1000 \pm 50 \mathrm{ppm}$ $\mathrm{CO}_{2}$ concentrations when measured at sea level and $77^{\circ} \mathrm{F}\left(25^{\circ} \mathrm{C}\right)$.

\section{Discussion of Recommendation 2}

The accuracy of $\mathrm{CO}_{2}$ sensors used for DCV must be improved if DCV systems are to provide the intended energy and indoor environmental quality benefits. Based on the previously-described research [6], restricting the allowable sensor designs will not assure widespread compliance with the Title 24 accuracy requirements. The studies of the accuracy of new $\mathrm{CO}_{2}$ sensors by the Iowa Energy Center [10] demonstrated that existing Title 24 requirements do not assure that a large majority of new $\mathrm{CO}_{2}$ sensors meet the accuracy requirements of Title 24. This recommended specification, if enforced, would assure that new $\mathrm{CO}_{2}$ sensors receive a calibration and are accurate within $\pm 75 \mathrm{ppm}$ when initially installed or shortly thereafter. Because sensor calibrations may change over the life of the sensor, such a sensor validation program would not assure that sensor accuracy is maintained.

The automated background calibration features present in many of the existing $\mathrm{CO}_{2}$ sensor technologies will adjust sensor calibrations based on the lowest $\mathrm{CO}_{2}$ concentrations experienced. After initial sensor deployment, the accuracy of $\mathrm{CO}_{2}$ measurements may improve (or occasionally degrade) over a period of a few weeks. Thus, for sensors with an automated background calibration feature, it may be preferable to perform the on-site calibration after 30 days of deployment. Manufacturer's protocols should specify when on-site calibrations should be performed after initial sensor deployment.

This requirement will increase the cost of installing DCV systems by an amount that has not been determined. The resulting energy savings will reduce energy costs by an amount that has not been determined. 


\section{Recommendation 3}

Description of Recommendation 3

All $\mathrm{CO}_{2}$ sensors shall have a continuously-readable visual display of the current $\mathrm{CO}_{2}$ concentration on the sensor. Manufacturer's may provide a cover that makes the display accessible to facility managers but not to other building occupants.

\section{Discussion of Recommendation 3}

Displays of the currently measured $\mathrm{CO}_{2}$ concentrations on the $\mathrm{CO}_{2}$ sensors may make facility managers more aware of faulty sensors that require calibration or replacement. The research described above has shown that sensors that do not respond to changes in $\mathrm{CO}_{2}$ concentrations and sensors with very large easily recognizable measurement errors are sometimes deployed in buildings [6]. Displays of $\mathrm{CO}_{2}$ concentration should also make it easier for controls contractors and facility managers to assure that $\mathrm{CO}_{2}$ concentration at the energy management and control system matches the concentration at the sensor, e.g. make it easier to detect and avoid signal processing errors. Finally, displays will facilitate the process of calibrating deployed $\mathrm{CO}_{2}$ sensors.

\section{Recommendation 4}

\section{Description of Recommendation 4}

Change the existing specification in Title 24 that reads as follows " $\mathrm{CO}_{2}$ sensors shall be located in the room between $3 \mathrm{ft}$ and $6 \mathrm{ft}(0.9$ and $1.8 \mathrm{~m})$ above the floor or at the anticipated height of the occupants heads" to " $\mathrm{CO}_{2}$ sensors shall be located in the room between $3 \mathrm{ft}$ and $6 \mathrm{ft}$ ( 0.9 and $1.8 \mathrm{~m}$ ) above the floor or at the anticipated height of the occupant's heads or in the return air duct if the return air duct contains only air from the room for which demand controlled ventilation is implemented. Sensors shall not be installed in return air ducts if the room has a ventilation system designed to produce a displacement air flow pattern between the floor and the ceiling or if the ceiling is more than $14 \mathrm{ft}(4.3 \mathrm{~m})$ above the floor. Sensors shall not be installed in returnair plenums or at the plane of the return-air grille.”

\section{Discussion of Recommendation 4}

The research summarized above found that $\mathrm{CO}_{2}$ concentrations at different locations on walls of meeting rooms could differ by more than $200 \mathrm{ppm}$ and fluctuate considerably with time [6]. The study was too small for definitive conclusions; however, relative to a $\mathrm{CO}_{2}$ measurement at a single location on a meeting room wall, a measurement in a return air duct appears to be as representative, and possibly more representative, of the average $\mathrm{CO}_{2}$ concentration in the room. $\mathrm{CO}_{2}$ sensors installed on walls may be exposed to air from within wall cavities if the room is slightly depressurized relative to the wall cavity because the electrical wiring for wall-mounted sensors normally extends through an unsealed hole in the wall behind the sensor. Also, wallmounted sensors may occasionally be exposed to the jets of low- $\mathrm{CO}_{2}$ supply air as these jets can flow across ceilings and down walls. The existing prohibition against duct-mounted sensors was likely motivated by concerns that low- $\mathrm{CO}_{2}$ supply air exiting a ceiling mounted supply air 
diffuser may short circuit to a return grille, causing the return air $\mathrm{CO}_{2}$ concentration to be substantially lower than the average concentration in the room. While such short circuiting can occur, studies of indoor air flow made using tracer gases in rooms with traditional high velocity air supplies indicate that substantial short circuiting is not common [11]. Measurable short circuiting is most likely when the supply air is used for heating [12] and prolonged heating of meeting rooms with a high occupant density, where DCV is required, may be uncommon. Thus, while there is not enough evidence to justify requiring that $\mathrm{CO}_{2}$ sensors be installed in return ducts as opposed to on walls, there is also not sufficient justification to prohibit locating $\mathrm{CO}_{2}$ sensors in return ducts. The prohibition against duct mounted sensors when the ceiling is more than $14 \mathrm{ft}(4.3 \mathrm{~m})$ above the floor is a judgment-based precaution as concentration differences between the occupied zone and the ceiling may be larger when the ceiling height is large. No data were identified confirming that duct-mounted sensors are inappropriate in rooms with high ceilings.

\section{Recommendation 5}

\section{Description of Recommendation 5}

Change the existing specification in Title 24 that reads as follows "For each system with demand control ventilation, $\mathrm{CO}_{2}$ sensors shall be installed in each room that meets the criteria of Section 121(c)3B with no less than one sensor per 10,000 $\mathrm{ft}^{2}$ of floor space." to "For each system with demand control ventilation, $\mathrm{CO}_{2}$ sensors shall be installed in each room that meets the criteria of Section 121(c)3B with no less than one sensor per 10,000 ft' ${ }^{2}$ of floor space. In addition to standalone sensors that measure the $\mathrm{CO}_{2}$ concentration at a single location, measurements may be performed with measurement systems that use tubing, valves, and pumps to measure at multiple indoor locations with a single $\mathrm{CO}_{2}$ sensor if data are available from each location at least once every 10 minutes.”

\section{Discussion of Recommendation 5}

The purpose of this proposed change in Title 24 language it to make prospective users more aware of multi-location $\mathrm{CO}_{2}$ measurement systems which tend to use higher quality $\mathrm{CO}_{2}$ sensors and incorporate an outdoor air $\mathrm{CO}_{2}$ measurement, both of which can improve accuracy of determining the indoor-to-outdoor $\mathrm{CO}_{2}$ concentration differences. Pilot scale studies of the multi-location $\mathrm{CO}_{2}$ measurement systems were too limited for firm conclusions about system accuracy but the findings were encouraging [6].

\section{Recommendation 6.}

Description of Recommendation 6

The required types of building spaces for which DCV is required in Title 24 should not be expanded to include general office spaces' however, DCV should continue to be optional for general office spaces.

\section{Discussion of Recommendation 6}

Model results, summarized above, evaluated the potential energy savings and cost effectiveness of implementing DCV in general office spaces. Given the model findings and the uncertainty about minimum ventilation rates in the existing office building stock, there is a large uncertainty 
about the cost effectiveness of DCV in general office spaces in California climates. Consequently, we do not recommend requiring DCV in general office spaces.

\section{Recommendation 7.}

Description of Recommendation 7

At this time, Title 24's specifications pertaining to DCV should not be modified to allow use of optical people counting, in place of $\mathrm{CO}_{2}$ sensors, to provide the control signal for DCV.

\section{Discussion of Recommendation 7}

Pilot scale studies were completed to evaluate the performance of two optical people counting systems potentially suitable for use in DCV systems [7].. The counting errors were generally small, indicating the long-term potential of applying people counting for DCV. However, in some highly demanding situations counting errors were large. Further research is needed, and product improvements may be necessary, before one can be confident that optical people counting systems provide a sufficiently accurate count of people to serve as a control signal for DCV.

\section{DISCUSSION}

Changes in DCV sensor technologies and practices are necessary if DCV is to consistently save energy and assure adequate ventilation. Based on the results of a multi-faceted research effort, this document describes five recommended changes to the specifications in Title 24 for DCV and makes two recommendations to not change aspects of Title 24. Enacting the suggested recommendations should help DCV to achieve its potential but they will definitely not eliminate all sensing problems in DCV systems. Further research to evaluate and develop alternatives to the widely used low-cost single location non-dispersive infrared $\mathrm{CO}_{2}$ sensor may be needed if DCV is to reach its full potential. Although the recommendations in this report were developed with input from the California Energy Commission and the Iowa Energy Center, a thorough evaluation all of the ramifications of implementing these recommendations was beyond the scope of the supporting research project. Consequently, the California Energy Commission will need to further evaluate these recommendations.

\section{ACKNOWLEDGMENTS}

The authors thank Brad Meister of the California Energy Commission for project management and the following individuals for their input in the process leading to these recommendations: Brad Meister, Martha Brook, Maziar Shirakh, Curt Klaassen, Xiaohui Zhou, Michael McGaraghan, Jim Meacham, and Cathy Chappell. The authors also thank Curt Klaassen and Mike Apte for reviewing a draft of this document. 


\section{APPENDIX 1. Excepts of specifications for DCV in Title 24 and its appendices.}

\section{Section 121 - Requirements for Ventilation}

All nonresidential, high-rise residential, and hotel/motel occupancies shall comply with the requirements of Section 121(a) through 121(e).

\section{(a) General Requirements.}

1. All enclosed spaces in a building that are normally used by humans

Required Demand Control Ventilation. HVAC systems with the following characteristics shall have demand ventilation controls complying with 121(c)4:

A. They have an air economizer; and

B. They serve a space with a design occupant density, or a maximum occupant load factor for egress purposes in the CBC, greater than or equal to 25 people per $1000 \mathrm{ft} 2$ (40 square foot per person); and

C. They are either:

i. Single zone systems with any controls; or

ii. Multiple zone systems with Direct Digital Controls (DDC) to the zone level.

EXCEPTION 1 to Section 121(c)3: Classrooms, call centers, office spaces served by multiple zone systems that are continuously occupied during normal business hours with occupant density greater than 25 people per $1000 \mathrm{ft}^{2}$ per Section 121(b)2B, healthcare facilities and medical buildings, and public areas of social services buildings are not required to have demand control ventilation.

EXCEPTION 2 to Section 121(c)3: Where space exhaust is greater than the design ventilation rate specified in Section 121(b)2B minus $0.2 \mathrm{cfm}$ per $\mathrm{ft}^{2}$ of conditioned area.

EXCEPTION 3 to Section 121(c)3: Spaces that have processes or operations that generate dusts, fumes, mists, vapors, or gases and are not provided with local exhaust ventilation, such as indoor operation of internal combustion engines or areas designated for unvented food service preparation, or beauty salons shall not install demand control ventilation.

EXCEPTION 4 to Section 121(c)3: Spaces with an area of less than 150 square feet, or a design occupancy of less than 10 people per Section 121(b)2B.

\section{Demand Control Ventilation Devices.}

A. For each system with demand control ventilation, CO2 sensors shall be installed in each room that meets the criteria of Section 121(c)3B with no less than one sensor per 10,000 $\mathrm{ft}^{2}$ of floor space. When a zone or a space is served by more than one sensor, signal from any sensor indicating that $\mathrm{CO} 2$ is near or at the setpoint within a space, shall trigger an increase in ventilation to the space; $\mathrm{B}$. CO2 sensors shall be located in the room between $3 \mathrm{ft}$ and $6 \mathrm{ft}$ above the floor or at the anticipated height of the occupants heads;

\section{SECTION 121 - REQUIREMENTS FOR VENTILATION}

2008 Building Energy Efficiency Standards Page 75

C. Demand ventilation controls shall maintain CO2 concentrations less than or equal to $600 \mathrm{ppm}$ plus the outdoor air $\mathrm{CO} 2$ concentration in all rooms with $\mathrm{CO} 2$ sensors;

EXCEPTION to Section 121(c)4C: The outdoor air ventilation rate is not required to be larger than the design outdoor air ventilation rate required by Section 121(b)2 regardless of CO2 concentration. 
D. Outdoor air CO2 concentration shall be determined by one of the following:

i. CO2 concentration shall be assumed to be $400 \mathrm{ppm}$ without any direct measurement; or ii. $\mathrm{CO} 2$ concentration shall be dynamically measured using a $\mathrm{CO} 2$ sensor located within $4 \mathrm{ft}$ of the outdoor air intake.

E. When the system is operating during hours of expected occupancy, the controls shall maintain system outdoor air ventilation rates no less than the rate listed in TABLE 121-A times the conditioned floor area for spaces with CO2 sensors, plus the rate required by Section 121(b)2 for other spaces served by the system, or the exhaust air rate whichever is greater;

F. CO2 sensors shall be certified by the manufacturer to be accurate within plus or minus $75 \mathrm{ppm}$ at a 600 and $1000 \mathrm{ppm}$ concentration when measured at sea level and $25^{\circ} \mathrm{C}$, factory calibrated or calibrated at start-up, and certified by the manufacturer to require calibration no more frequently than once every 5 years. Upon detection of sensor failure, the system shall provide a signal which resets to supply the minimum quantity of outside air to levels required by Section 121(b)2 to the zone serviced by the sensor at all times that the zone is occupied.

G. The CO2 sensor(s) reading for each zone shall be displayed continuously, and shall be recorded on systems with DDC to the zone level.

\section{Section 125 - Required Nonresidential Mechanical System Acceptance}

(a) Before an occupancy permit is granted the following equipment and systems shall be certified as meeting the Acceptance Requirements for Code Compliance, as specified by the Reference Nonresidential Appendix NA7. A Certificate of Acceptance shall be submitted to the enforcement agency that certifies that the equipment and systems meet the acceptance requirements:

5. Demand control ventilation systems required by Section 121(c)3 shall be tested in accordance with NA7.5.5

\section{NA7.5.5 Demand Control Ventilation (DCV) Systems NA7.5.5.1 Construction Inspection}

Prior to Functional Testing, verify and document the following:

- Carbon dioxide control sensor is factory calibrated or field-calibrated per §121(c)4.

- The sensor is located in the high density space between $3 \mathrm{ft}$ and $6 \mathrm{ft}$ above the floor or at the anticipated level of the occupants' heads.

- DCV control setpoint is at or below the $\mathrm{CO}_{2}$ concentration permitted by $\$ 121(\mathrm{c}) 4 \mathrm{C}$. NA7.5.5.2 Functional Testing

Step 1: Disable economizer controls

Step 2: Simulate a signal at or slightly above the $\mathrm{CO}_{2}$ concentration setpoint required by §121(c)4C. Verify and document the following:

- For single zone units, outdoor air damper modulates open to satisfy the total ventilation air called for in the Certificate of Compliance.

- For multiple zone units, either outdoor air damper or zone damper modulate open to satisfy the zone ventilation requirements.

Step 3: Simulate signal well below the $\mathrm{CO}_{2}$ setpoint. Verify and document the following:

- For single zone units, outdoor air damper modulates to the design minimum value.

- For multiple zone units, either outdoor air damper or zone damper modulate to satisfy the reduced zone ventilation requirements. 
Step 4: Restore economizer controls and remove all system overrides initiated during the test. Step 5: With all controls restored, apply $\mathrm{CO}_{2}$ calibration gas at a concentration slightly above the setpoint to the sensor. Verify that the outdoor air damper modulates open to satisfy the total ventilation air called for in the Certificate of Compliance. 


\section{REFERENCES}

1. Persily, A.K., Evaluating building IAQ and ventilation with carbon dioxide. ASHRAE Transactions, 1997. 103(2): p. 193-204.

2. Apte, M.G., A review of demand controlled ventilation, in Healthy Buildings 2006. 2006: Universidade de Porto, Portugal. p. 371-376.

3. Emmerich, S.J. and A.K. Persily, State of the art review of $\mathrm{CO}_{2}$ demand controlled ventilation technology and application. ISTIR 6729. 2001, National Institute of Standards and Technology: Gaithersburgh, MD.

4. Fisk, W.J. and A.T. de Almeida, Sensor based demand controlled ventilation: a review. Energy and Buildings, 1998. 29(1): p. 35-44.

5. Brandemuehl, M.J. and J.E. Braun, The impact of demannd controlled and economizer ventilation strategies on energy use in buildings. ASHRAE Transactions, 1999. 105(2).

6. Fisk, W.J., et al., $\mathrm{CO}_{2}$ monitoring for demand controlled ventilation in commercial buildings. LBNL-xхxxx. 2010, Lawrence Berkeley National Laboratory: Berkeley, CA.

7. Fisk, W.J. and D.P. Sullivan, Optical people counting for demand controlled ventilation: a pilot study of counter performance, LBNL-3170E. 2009, Lawrence Berkeley National Laboratory: Berkeley, CA.

8. Hong, T. and W.J. Fisk, Assessment of energy savings potential from the use of demand control ventilation systems in general office spaces in California. LBNL-3165E. 2009, Lawrence Berkeley National Laboratory: Berkeley, CA.

9. California Energy Commission, 2008 Building energy efficiency standards for residential and nonresidential buildings CEC-400-2008-001-CMF. 2008, California Energy Commission: Sacramento, CA.

10. National Buildings Controls Information Program, Product testing report, wall mounted carbon dioxide $\left(\mathrm{CO}_{2}\right)$ transmitters. 2009, Iowa Energy Center: Ankeny, IA.

11. Fisk, W.J. and D. Faulkner, Air exchange effectiveness in office buildings: measurement techniques and results, in 1992 International Symposium on Room Air Convection and Ventilation Effectiveness. 1992, American Society of Heating, Refrigerating, and Air Conditioning Engineers, Inc.: Tokyo. p. 213-223.

12. Fisk, W.J., et al., Air change effectiveness and pollutant removal efficiency during adverse mixing conditions. Indoor Air, 1997. 7: p. 55-63. 